\title{
Variabilidade físico-química da farinha de mandioca
}

\author{
Physicochemical variability of cassava flour
}

\author{
Joana Maria Leite de SOUZA ${ }^{1 \star}$, Jacson Rondinelli da Silva NEGREIROS², Virgínia de Souza ÁLVARES ${ }^{3}$, \\ Felícia Maria Nogueira LEITE ${ }^{4}$, Maria Luzenira de SOUZA ${ }^{5}$, Fabiana Silva REIS ${ }^{6}$, \\ Francisco Álvaro Viana FELISBERTO ${ }^{7}$
}

\section{Resumo}

Este trabalho teve como objetivo avaliar a variabilidade físico-química da farinha de mandioca comercializada no município de Cruzeiro do Sul - AC por meio da análise multivariada. Foram analisadas 18 amostras de diferentes farinhas de mandioca, quanto às variáveis: umidade, cinzas, lipídios, proteína bruta, fibra bruta, carboidratos totais, acidez e pH. A aplicação da análise multivariada de agrupamento segundo o método de Tocher permitiu o estabelecimento de cinco grupos de farinhas. Os grupos IV e V foram considerados de alta qualidade, o primeiro por apresentar o menor teor de cinzas e o maior de proteína bruta, e o segundo por apresentar o menor teor de umidade e o maior teor de carboidratos dentre os grupos. As técnicas de análise multivariada foram coerentes para identificar as farinhas mais heterogêneas. A identificação de grupos distintos indica a existência de variabilidade nas farinhas de mandioca comercializadas na região de Cruzeiro do Sul - AC, podendo esta variabilidade estar relacionada, especialmente com o processo de produção.

Palavras-chave: farinha de mandioca; heterogeneidade; análise multivariada.

\begin{abstract}
The goal of this work was to evaluate the physicochemical variability of the cassava flour, sold in the city of Cruzeiro do Sul - in the state of AC (Brazil), by multivaried analysis. The following contents of eighteen different cassava flours were analyzed: moisture, ashes, lipids, protein, fiber, carbohydrates, acidity, and pH. Grouping multivaried analysis according to the Tocher method allowed the establishment of five groups of flours. The groups IV and V were considered high quality groups. The first one due to the lower ashes and higher protein contents; and the second due to the lower moisture and higher carbohydrates contents. The multivaried analysis techniques presented good responses to identify most heterogeneous flours. The physicochemical variability seen in the five different groups probably indicates different production processes. Keywords: cassava flour; heterogeneous; multivaried analysis.
\end{abstract}

\section{Introdução}

A farinha é o principal derivado da mandioca para a alimentação humana no Brasil, visto ser consumida em todo o País, chegando a ser, em algumas regiões do Norte e Nordeste, a principal fonte energética. Apesar de a farinha constituir a forma mais ampla de aproveitamento industrial da mandioca, ela não é um produto muito valorizado, sobretudo pela elevada variabilidade de tipos de farinha, o que dificulta a comercialização.

Essas diferenças nas farinhas oferecidas ao mercado são decorrentes de vários fatores como cultivar, clima, solo, ponto de colheita, variabilidade genética, matéria-prima e outros, mas o principal fator responsável é o método de processamento. Segundo Lima (1982), a heterogeneidade da farinha é devida, principalmente, à fabricação por pequenos produtores para seu uso diário.
No Estado do Acre, a farinha de mandioca é processada de forma artesanal em pequenas unidades denominadas casas-de-farinha, que utilizam matéria-prima e mão-de-obra provenientes da agricultura familiar, e grande parte está localizada no próprio local de produção da matéria-prima. Nestes estabelecimentos, cada produtor segue um processo próprio de fabricação da farinha. Cereda (2005) cita que fornos muito quentes ou frios, cargas grandes ou muito pequenas, prensagem mais ou menos intensiva são alguns dos fatores que podem influenciar o padrão de qualidade da farinha. Essas variações tornam quase impossível a proposta de um padrão nacional de qualidade. Mesmo em uma única propriedade, por conseqüência do sistema artesanal de produção, é raro ocorrer uniformidade em fabricações sucessivas.

${ }^{2}$ Embrapa Acre - CPAF-AC, Genética e Melhoramento de Plantas, BR 364, Km 14, CEP 69908-970. Rio Branco - AC, Brasil, E-mail: jacson@cpafac.embrapa.br

${ }_{3}^{3}$ Embrapa Acre - CPAF-AC, Laboratório de Tecnologia de Alimentos, BR 364, Km 14, CEP 69908-970. Rio Branco - AC, Brasil, E-mail: virginia@cpafac.embrapa.br

${ }^{4}$ Secretaria de Estado de Extensão Agroflorestal e Produção Familiar - SEAPROF, CEP 69908-620, Rio Branco - AC, Brasil, E-mail: felicialeite@hotmail.com

${ }_{5}^{5}$ Departamento de Produção Vegetal, Universidade Federal do Acre, UFAC, BR-364, 6637, Km 04, Distrito Industrial, CEP 69.915-900, Rio Branco - AC, Brasil, E-mail: mluzen@hotmail.com

${ }^{6}$ Embrapa Acre - CPAF-AC, Laboratório de Tecnologia de Alimentos, BR 364, Km 14, CEP 69908-970, Rio Branco - AC, Brasil, E-mail: fabianasilvareis@hotmail.com

7 Embrapa Acre - CPAF-AC, Laboratório de Bromatologia, BR 364, Km 14, CEP 69908-970, Rio Branco - AC, Brasil, E-mail: alvaro@cpafac.embrapa.br

${ }^{*}$ A quem a correspondência deve ser enviada 
As técnicas de estatística multivariada que permitem a quantificação da dissimilaridade pela distância, assim como análises de agrupamento, podem ser instrumentos úteis na identificação de produtores que fabricam farinha de mandioca com características semelhantes, contribuindo para a comercialização unificada envolvendo vários produtores, possibilitando a uniformidade do produto comercializado.

Dentre os métodos de análises multivariadas existentes, a análise de agrupamento pode ser importante ferramenta, a qual tem por objetivo reunir, por algum critério de classificação, a unidade amostral em vários grupos, de modo que exista homogeneidade dentro do grupo e heterogeneidade entre grupos; tais técnicas podem ser complementadas com a análise de componentes principais (CRUZ et al., 2004).

Desta forma, o objetivo deste trabalho foi analisar a variabilidade físico-química da farinha de mandioca comercializada no município de Cruzeiro do Sul - AC por meio de análise multivariada.

\section{Material e métodos}

\subsection{Material}

Amostras de farinha de mandioca foram coletadas, em novembro de 2006, em 14 casas-de-farinha nos municípios de Cruzeiro do Sul, Mâncio Lima e Rodrigues Alves - AC, onde foram processadas de forma artesanal em fornos que não possuem sistema de controle de temperatura. Os tratamentos foram compostos pelas diferentes farinhas obtidas, conforme descrição na Tabela 1, sendo que os tratamentos 1, 2, 3 e 4 foram provenientes de classificações particulares de um mesmo fabricante, em que: $\mathrm{T} 1$ = farinha com coco; $\mathrm{T} 2$ = farinha grossa, $\mathrm{T} 3$ = farinha peneirada e T4 = farinha com açafrão.

As amostras coletadas, de aproximadamente $1 \mathrm{~kg}$ cada, foram acondicionadas em sacos plásticos e transportadas via aérea para a cidade de Rio Branco, Acre, onde foram encaminhadas para o Laboratório de Tecnologia de Alimentos da Empresa Brasileira de Pesquisa Agropecuária (Embrapa-AC).

\subsection{Caracterização físico-química}

- Teor de umidade - determinado de acordo com o método 31.1.02 da AOAC (1995), usando-se estufa a $105^{\circ} \mathrm{C}$ por 8 horas.

- Teor de cinzas - as amostras foram carbonizadas até cessar a liberação de fumaça e, posteriormente, calcinadas em mufla a $540{ }^{\circ} \mathrm{C}$ até peso constante, segundo o método 31.1.04 da AOAC (1995).

- Teor de lipídios - obtido por extração em Soxhlet durante 10 horas e posterior evaporação do solvente, de acordo com o método 31.4.02 da AOAC (1995).

- Teor de proteínas - determinado pela técnica de micro-Kjeldahl, baseado em hidrólise e posterior destilação da amostra, utilizando o fator $6,25 \times \% \mathrm{~N}$, de acordo com o método 31.1.08 da AOAC (1995).

- Teor de fibra bruta - através de digestão do material em solução de $\mathrm{H}_{2} \mathrm{SO}_{4}$ a $1,25 \%$ p/v por 30 minutos, seguida de $\mathrm{NaOH} 1,25 \% \mathrm{~m} / \mathrm{v}$ por mais 30 minutos, de acordo com AOAC (1995).

- Carboidratos - estimados por diferença, subtraindo de 100 o somatório de proteínas, lipídios, cinzas, umidade e fibra bruta e os resultados expressos em percentual, segundo Normas Analíticas do Instituto Adolfo Lutz (1976).

- Acidez total titulável - determinado de acordo com o método 942.15 da AOAC (1995).

- pH 9 g da amostra foram misturadas em $60 \mathrm{~mL}$ de água destilada, homogeneizados e deixados em repouso por 30 minutos. A leitura foi feita em medidor de $\mathrm{pH}$ digital.

Tabela 1. Identificação dos tratamentos utilizados.

\begin{tabular}{ccc}
\hline Tratamentos & Origem/localidade & Cultivar/variedade \\
\hline T1 & Alto Pentecostes/Cruzeiro do Sul/Acre & Caboquinha \\
T2 & Alto Pentecostes/Cruzeiro do Sul/Acre & Caboquinha \\
T3 & Alto Pentecostes/Cruzeiro do Sul/Acre & Caboquinha \\
T4 & Alto Pentecostes/Cruzeiro do Sul/Acre & Caboquinha \\
T5 & Ramal do Macaxeira/Assis Brasil/Acre & Branquinha \\
T6 & Alto Pentecostes/Cruzeiro do Sul/Acre & Chico Anjo \\
T7 & Ramal do Macaxeira/Assis Brasil/Acre & Mansa e Brava \\
T8 & Alto Pentecostes/Cruzeiro do Sul/Acre & Branquinha \\
T9 & Aldeia Poyaunawa/Mâncio Lima/Acre & Branquinha \\
T10 & Ramal do Barão/Mâncio Lima/Acre & Branquinha \\
T11 & Ramal do Barão/Mâncio Lima/Acre \\
T12 & Ramal do Barão/Mâncio Lima/Acre & Branquinha + Chico Anjo \\
T13 & Ramal do Barão/Mâncio Lima/Acre & Branquinha \\
T14 & Alto Pentecostes/Cruzeiro do Sul/Acre & Chico Anjo \\
T15 & Aldeia Poyaunawa/Mâncio Lima/Acre & Branquinha \\
T16 & Ramal Barão/Cruzeiro do Sul/Acre & Branquinha + Chico Anjo \\
T17 & Ramal Barão/Cruzeiro do Sul/Acre & Branquinha \\
T18 & Ramal do Japãozinho/Cruzeiro do Sul/Acre & Branquinha \\
\hline
\end{tabular}

$\mathrm{T} 1$ = farinha com coco; T2 = farinha grossa; T3 = farinha peneirada; T4 = farinha com açafrão; e de T5 a T18 = farinhas comuns de diferentes produtores. 


\subsection{Análise estatística dos resultados}

A variabilidade entre as 18 amostras de farinhas de mandioca foi estimada por análise de agrupamento em que a medida de dissimilaridade utilizada foi a distância euclidiana média padronizada. As distâncias euclidianas médias entre cada par de farinhas foram calculadas segundo Cruz et al. (2004) (Equação 1):

$\mathrm{X}_{\mathrm{ij}}=\mathrm{X}_{\mathrm{ij}} / \mathrm{S}\left(\mathrm{X}_{\mathrm{j}}\right)$

em que $\mathrm{S}\left(\mathrm{X}_{\mathrm{j}}\right)$ é o desvio padrão dos dados do j-ésimo caráter (Equação 2), então:

$\mathrm{d}_{\mathrm{ii}}=\sqrt{\frac{1}{\mathrm{n}} \sum_{\mathrm{j}}\left(\mathrm{x}_{\mathrm{ij}}-\mathrm{x}_{\mathrm{i}^{\prime} \mathrm{j}}\right)^{2}}$

em que dii' é a distância euclidiana média baseada em dados padronizados e n é o número de caracteres analisados. Essa distância foi escolhida pelo fato de os dados terem sido coletados em experimento que não envolve delineamento experimental. Obteve-se, assim, uma matriz de distância pxp, em que $\mathrm{p}=18$. Posteriormente, aplicou-se o método aglomerativo de otimização de Tocher (RAO, 1952) para a formação dos grupos, o qual teve como critério o valor máximo da medida de dissimilaridade encontrado no conjunto das menores distâncias envolvendo cada tratamento. Outro método de agrupamento utilizado foi o método hierárquico do vizinho mais próximo para formação de um dendrograma entre os grupos de produtores.

Foi quantificada a contribuição relativa dos caracteres para o estudo da variabilidade da farinha comercializada, utilizando o critério proposto por Singh (1981). Foi utilizado o aplicativo computacional Genes - versão 2007 (CRUZ, 2001) para auxiliar nas análises estatísticas.

\section{Resultados e discussão}

Os resultados das determinações físico-químicas das 18 amostras de farinha de mandioca estão apresentados na Tabela 2. Observou-se em relação aos valores de umidade, cinzas, acidez e carboidratos que todas as amostras estão de acordo com os padrões estabelecidos pela Legislação Brasileira para farinhas de mandioca, Portaria no 554 de 30.08.1995 da Secretaria da Agricultura, do Abastecimento e Reforma Agrária (BRASIL, 1995), que estabelece valores máximos de $13 \%$ de umidade, 1,5\% de cinzas, 3\% de acidez e o mínimo de 70 a $75 \%$ para carboidratos.

As farinhas analisadas apresentaram variações nas características apresentadas, com teores de 8,10 a 12,02\% para umidade; de 0,38 a $0,93 \%$ em cinzas; de 0,85 a $2,58 \%$ de proteína bruta; de 0,21 a $1,91 \%$ de lipídios; de 1,60 a $2,71 \%$ para fibra bruta; de 83,34 a $88,36 \%$ de carboidratos totais; de 1,09 a 2,89 meq $\mathrm{NaOH} .100 \mathrm{~g}^{-1}$ de acidez; e de 4,53 a 4,95 para pH (Tabela 2). Estes resultados estão de acordo com os encontrados por Dias e Leonel (2006), Aryee et al. (2006), Ferreira Neto et al. (2003) e Paiva (1991).

Com base nos dados físico-químicos obtidos a partir das amostras de farinhas coletadas, obteve-se como medida de dissimilaridade, a distância euclidiana média padronizada, a qual foi utilizada para a formação dos grupos.

A Tabela 3 apresenta os grupos de farinha e as médias de cada grupo quanto às análises físico-químicas obtidas. Por meio do agrupamento de Tocher, verifica-se que as 18 amostras de farinhas avaliadas propiciaram a formação de 5 grupos distintos de farinha.

Constata-se na Tabela 3 que o grupo I foi formado pela maioria dos tratamentos, constituído por 12 destes (amostras diferentes): $1,2,4,5,8,9,10,12,14,16,17,18$, os quais apresentaram valores médios entre os demais grupos para todas as características físico-químicas avaliadas.

O grupo II, constituído pelos tratamentos 11, 13 e 15, foi considerado o de menor interesse por apresentar o maior teor médio de umidade $(11,31 \%)$, além dos menores teores de proteína bruta $(0,93 \%)$ e de carboidratos $(84,02 \%)$. Apenas a acidez, menor valor médio dentre os grupos (1,47 meq NaOH.100 g $\left.{ }^{-1}\right)$, foi a característica considerada adequada para as farinhas deste grupo.

A avaliação do teor de umidade da farinha de mandioca tem grande importância, em razão da sua influência na vida de prateleira de alimentos, tendo em vista que níveis maiores que $13 \%$ podem proporcionar crescimento microbiano e deterioração em curto tempo. Dessa forma, baixos percentuais de umidade são favoráveis a uma maior estabilidade e vida-de-prateleira do produto. Em características como cinzas, proteínas e lipídios pode haver variações entre as amostras de farinha devido às características intrínsecas das raízes da mandioca. Contudo, o teor de umidade, por exemplo, está relacionado com o seu processo de fabricação (CHISTÉ et al., 2006).

Como todas as amostras neste trabalho foram coletadas logo depois de concluído o processamento da farinha, certamente o maior teor de umidade encontrado nas amostras (tratamentos) do grupo II (Tabela 3) foi devido a uma menor temperatura e/ou tempo de torração, parâmetros que geralmente não são medidos nos processos de fabricação artesanal.

Além destas características, este grupo teve o maior valor médio de fibra bruta de todos os grupos (Tabela 3). As fibras alimentares exercem funções gastrintestinais através de sua ação física, capacidade de hidratação e de aumentar o volume e a velocidade de trânsito do bolo alimentar e fecal. Possuem também a capacidade de complexar-se com outros constituintes da dieta por meio de vários mecanismos, podendo arrastá-los em maior quantidade na excreção fecal. Dessa forma, tanto nutrientes essenciais, como proteínas, minerais e vitaminas, como substâncias tóxicas, poderão ser excretadas em maior ou menor quantidade, dependendo da qualidade e da quantidade da fibra presente na dieta (RAUPP et al., 1999).

Mattos e Martins (2000) classificaram os alimentos de acordo com o seu teor de fibras: baixo (inferior a 2,4 g fibras/100 g), moderado (de 2,4 a 4,4 $\mathrm{g}$ fibras/100 g) ou alto (superior a 4,4 g fibras/100 g). De acordo com essa classificação, as farinhas do grupo II apresentaram teor moderado $(2,54 \%)$ e os demais grupos, teor baixo de fibras (de 1,60 a 2,36\%) (Tabela 3).

O grupo III, constituído apenas pelo tratamento 6, também não se incluiu como um grupo de farinha de boa qualidade, já que teve o maior valor de cinzas (0,93\%). Outras características contrastantes com demais grupos foram o maior teor de lipídios 
$(1,91 \%)$ e maior $\mathrm{pH}(4,85)$ encontrado dentre todas as médias (Tabela 3).

$\mathrm{O}$ pH é um fator de grande importância na limitação da capacidade de desenvolvimento de microrganismos no alimento. Em função deste parâmetro, de acordo com Soares et al. (1992), os alimentos podem ser classificados em: pouco ácidos $(\mathrm{pH}>4,5)$, ácidos $(4,5$ a 4,0) e muito ácidos $(<4,0)$. Diante desta classificação, todas as amostras de farinha analisadas foram consideradas pouco ácidas, apresentando pH superior a 4,53 (Tabela 3).

O grupo IV foi constituído somente pelo tratamento 7, considerado de alta qualidade por apresentar o menor teor de cinzas $(0,38 \%)$ e maior teor de proteína bruta $(2,58 \%)$ (Tabela 3$)$.

As cinzas são o resíduo mineral fixo resultante da incineração da amostra do produto (BRASIL, 1995) e valores maiores que a tolerância máxima permitida na Legislação Brasileira, 1,5\%, po- dem ser um indicativo de teores significativos de $\mathrm{Ca}, \mathrm{P}, \mathrm{Fe}$ e $\mathrm{Mg}$, como também, mais provavelmente, indicam contaminação por material estranho ao produto ocasionado por falhas em algumas etapas do processamento (PAIVA, 1991). Trabalho realizado por Souza e Menezes (2004) mostra a composição centesimal da farinha de mandioca, proveniente de matéria-prima cultivada, processada e comercializada em Campinas-SP, na qual o valor de cinzas foi 0,74\%, dentro do limite estabelecido pela legislação. Desta forma, níveis baixos de cinzas na farinha de mandioca são favoráveis para uma maior qualidade desta.

As farinhas em geral apresentam um teor de proteínas bastante baixo, o que já é esperado frente à composição da raiz da mandioca (ALBUQUERQUE et al., 1993). Desta forma, um elevado teor de proteína na farinha de mandioca é recomendado, sendo este dependente da variedade utilizada. Souza e Menezes (2004) encontraram $1,21 \%$ de proteína na farinha obtida em

Tabela 2. Valores médios, em percentagem, do teor de Umidade (U), Cinzas (CZ), Lipídios (LI), Proteína Bruta (PB), Fibra Bruta (FB), Carboidratos Totais (CB), Acidez (AC) e pH nas farinhas de mandioca de Cruzeiro do Sul - Acre.

\begin{tabular}{|c|c|c|c|c|c|c|c|c|}
\hline \multirow[t]{2}{*}{ Tratamentos } & $\mathrm{U}$ & $\mathrm{CZ}$ & $\mathrm{PB}$ & LI & FB & $\mathrm{CB}$ & $\mathrm{AC}$ & \multirow[t]{2}{*}{${ }^{*} \mathrm{pH}$} \\
\hline & & \multicolumn{4}{|c|}{$\star \%$} & \multicolumn{2}{|r|}{${ }^{*}$ meq NaOH.100 g ${ }^{-1}$} & \\
\hline 1 & 8,43 & 0,70 & 0,92 & 1,67 & 1,77 & 86,52 & 2,26 & 4,66 \\
\hline 2 & 10,65 & 0,56 & 0,89 & 0,63 & 1,91 & 85,36 & 1,12 & 4,78 \\
\hline 3 & 8,10 & 0,45 & 1,01 & 0,48 & 1,60 & 88,36 & 2,89 & 4,65 \\
\hline 4 & 8,19 & 0,59 & 1,49 & 0,43 & 1,74 & 87,55 & 1,48 & 4,88 \\
\hline 5 & 9,41 & 0,38 & 1,07 & 0,66 & 1,64 & 86,85 & 2,60 & 4,65 \\
\hline 6 & 9,07 & 0,93 & 1,12 & 1,91 & 2,36 & 84,60 & 1,62 & 4,85 \\
\hline 7 & 9,24 & 0,38 & 2,58 & 0,33 & 2,25 & 85,23 & 2,06 & 4,69 \\
\hline 8 & 9,42 & 0,59 & 1,27 & 0,45 & 2,07 & 86,21 & 1,76 & 4,76 \\
\hline 9 & 10,55 & 0,84 & 1,23 & 0,23 & 1,93 & 85,22 & 2,16 & 4,54 \\
\hline 10 & 9,51 & 0,49 & 1,22 & 0,35 & 1,89 & 86,54 & 1,60 & 4,57 \\
\hline 11 & 12,02 & 0,82 & 1,00 & 0,40 & 2,42 & 83,34 & 1,13 & 4,87 \\
\hline 12 & 9,18 & 0,92 & 0,88 & 0,35 & 1,91 & 86,76 & 1,16 & 4,75 \\
\hline 13 & 10,57 & 0,88 & 0,94 & 0,45 & 2,50 & 84,67 & 1,82 & 4,53 \\
\hline 14 & 8,92 & 0,61 & 0,97 & 0,45 & 1,99 & 87,06 & 1,52 & 4,81 \\
\hline 15 & 11,33 & 0,84 & 0,85 & 0,21 & 2,71 & 84,06 & 1,46 & 4,69 \\
\hline 16 & 8,61 & 0,77 & 0,97 & 0,45 & 2,14 & 87,07 & 1,09 & 4,84 \\
\hline 17 & 9,45 & 0,60 & 0,93 & 0,38 & 1,94 & 86,70 & 1,95 & 4,65 \\
\hline 18 & 9,39 & 0,75 & 1,12 & 0,61 & 1,97 & 86,16 & 1,29 & 4,95 \\
\hline
\end{tabular}

${ }^{*}$ Média de 3 repetições para cada característica; T1 = farinha com coco; T2 = farinha grossa; T3 = farinha peneirada; T4 = farinha com açafrão; e de T5 a T18 = farinhas comuns de diferentes produtores.

Tabela 3. Grupos de farinha de mandioca e média das variáveis em cada grupo.

\begin{tabular}{|c|c|c|c|c|c|}
\hline \multirow[t]{2}{*}{ Itens $^{1}$} & \multicolumn{5}{|c|}{ Grupos } \\
\hline & $\mathrm{I}$ & II & III & IV & $\mathrm{V}$ \\
\hline Tratamentos & $\begin{array}{c}1,2,4,5,8,9,10,12 \\
14,16,17,18\end{array}$ & $11,13,15$ & 6 & 7 & 3 \\
\hline Determinação & \multicolumn{5}{|c|}{ Médias (\%) } \\
\hline $\mathrm{U}$ & 9,31 & 11,31 & 9,07 & 9,24 & 8,10 \\
\hline $\mathrm{CZ}$ & 0,65 & 0,85 & 0,93 & 0,38 & 0,45 \\
\hline $\mathrm{PB}$ & 1,08 & 0,93 & 1,12 & 2,58 & 1,01 \\
\hline LI & 0,55 & 0,35 & 1,91 & 0,33 & 0,48 \\
\hline FB & 1,91 & 2,54 & 2,36 & 2,25 & 1,60 \\
\hline $\mathrm{CB}$ & 86,50 & 84,02 & 84,60 & 85,23 & 88,36 \\
\hline $\mathrm{AC}$ & 1,66 & 1,47 & 1,62 & 2,06 & 2,89 \\
\hline $\mathrm{pH}$ & 4,74 & 4,70 & 4,85 & 4,69 & 4,65 \\
\hline
\end{tabular}

${ }^{1} \mathrm{U}=$ umidade (\%); $\mathrm{CZ}=$ cinzas (\%); $\mathrm{PB}=$ proteína bruta (\%); $\mathrm{LI}=$ lipídios (\%); FB = fibra bruta (\%); $\mathrm{CB}=$ carboidratos totais (\%); $\mathrm{AC}=$ acidez total titulável (meq NaOH.100 g-1);

$\mathrm{T} 1$ = farinha com coco; T2 = farinha grossa; T3 = farinha peneirada; T4 = farinha com açafrão; e de T5 a T18 = farinhas comuns de diferentes produtores. 
Campinas-SP, menor apenas que o valor encontrado para este grupo IV. Tal variação é pertinente à oscilação dos fatores que influenciam na composição química dos alimentos.

O grupo IV apresentou também o menor teor de lipídios dentre os demais grupos formados (0,33\%) (Tabela 3). A legislação brasileira não faz referência quanto ao valor de lipídios na farinha de mandioca, sendo que o seu teor está relacionado com as características intrínsecas do produto.

O grupo V, constituído somente pelo tratamento 3, apresentou características também consideradas adequadas para a farinha de mandioca de alta qualidade, principalmente, por apresentar o menor teor de umidade $(8,10 \%)$ e o maior teor de carboidratos (88,36\%) em relação aos demais grupos (Tabela 3).

O maior teor de carboidratos deste grupo pode estar relacionado com o menor teor de fibras $(1,60 \%)$, também encontrado na farinha deste grupo (Tabela 3). Do mesmo modo, no grupo II, o maior teor de fibras está associado ao menor teor de carboidratos encontrado.

Dentre as características analisadas, a acidez destaca-se como uma das mais importantes, estando relacionada com o processo de fabricação da farinha de mandioca, sugerindo a influência do tempo de fermentação da massa de mandioca triturada ou do tempo de prensagem. Dias e Leonel (2006) citam que acidez elevada pode ser indicativo de falta de higiene nas operações de processamento, o que é uma característica de processos artesanais. A exposição prolongada da massa de mandioca à temperatura ambiente elevada e o aumento no tempo de fermentação favorece, conseqüentemente, o aumento na acidez. No grupo V, composto pelo tratamento 3, a farinha analisada teve o maior valor de acidez dentre as demais $\left(2,89\right.$ meq $\left.\mathrm{NaOH} .100 \mathrm{~g}^{-1}\right)$.

Com base na matriz de distância Euclidiana média padronizada, gerou-se um dendrograma para formação dos grupos de acordo com o método do vizinho mais próximo (Figura 1).
Considerando-se uma distância de $60 \%$ no dendrograma, com base nas características avaliadas (Figura 1), verifica-se a formação de seis grupos. De acordo com este dendrograma, o grupo 1, reúne os tratamentos $8,14,16,10,17,12,18,4,3,5$ e 2 . O grupo 2 , os tratamentos 13, 15 e 11. Os grupos III, IV, V e VI os tratamentos 9, 1,6 e 7, respectivamente. A divergência entre eles mostra a ampla variabilidade nas farinhas produzidas na região. Portanto, pode-se considerar que, de um modo geral, os dois métodos de aglomeração fundamentados em dados físico-químicos foram coerentes na formação dos grupos de produtores de farinhas de mandioca coletadas no município de Cruzeiro do Sul.

Observa-se, pela formação dos grupos, que a variabilidade das farinhas não está representada pela variedade ou local de produção, já que não foram classificadas no mesmo grupo. A variabilidade pode estar relacionada principalmente pelo processo de fabricação, como citado por Lima (1982), podendo esta heterogeneidade ser encontrada em farinhas de um mesmo produtor.

A técnica de análise multivariada tem a vantagem, em relação aos métodos de análise univariada, de avaliar a importância de cada característica estudada sobre a variação total disponível entre os tratamentos avaliados, possibilitando o descarte dos caracteres menos discriminantes, por já estarem correlacionados com outras variáveis redundantes ou pela sua invariância.

$\mathrm{Na}$ Tabela 4, constam as contribuições relativas das variáveis para o estudo da variabilidade da farinha produzida. Carboidratos totais e umidade foram as variáveis que mais contribuíram para a variabilidade das farinhas de mandioca comercializadas no município, representando 78,55\% da variação total. Cinzas e pH foram as características de menor importância, provavelmente devido a sua menor invariância em relação às demais características avaliadas. Quanto à umidade, o processamento artesanal da farinha de mandioca sem o controle da temperatura de torração implica em variabilidade nesta característica encontrada nas amostras analisadas.

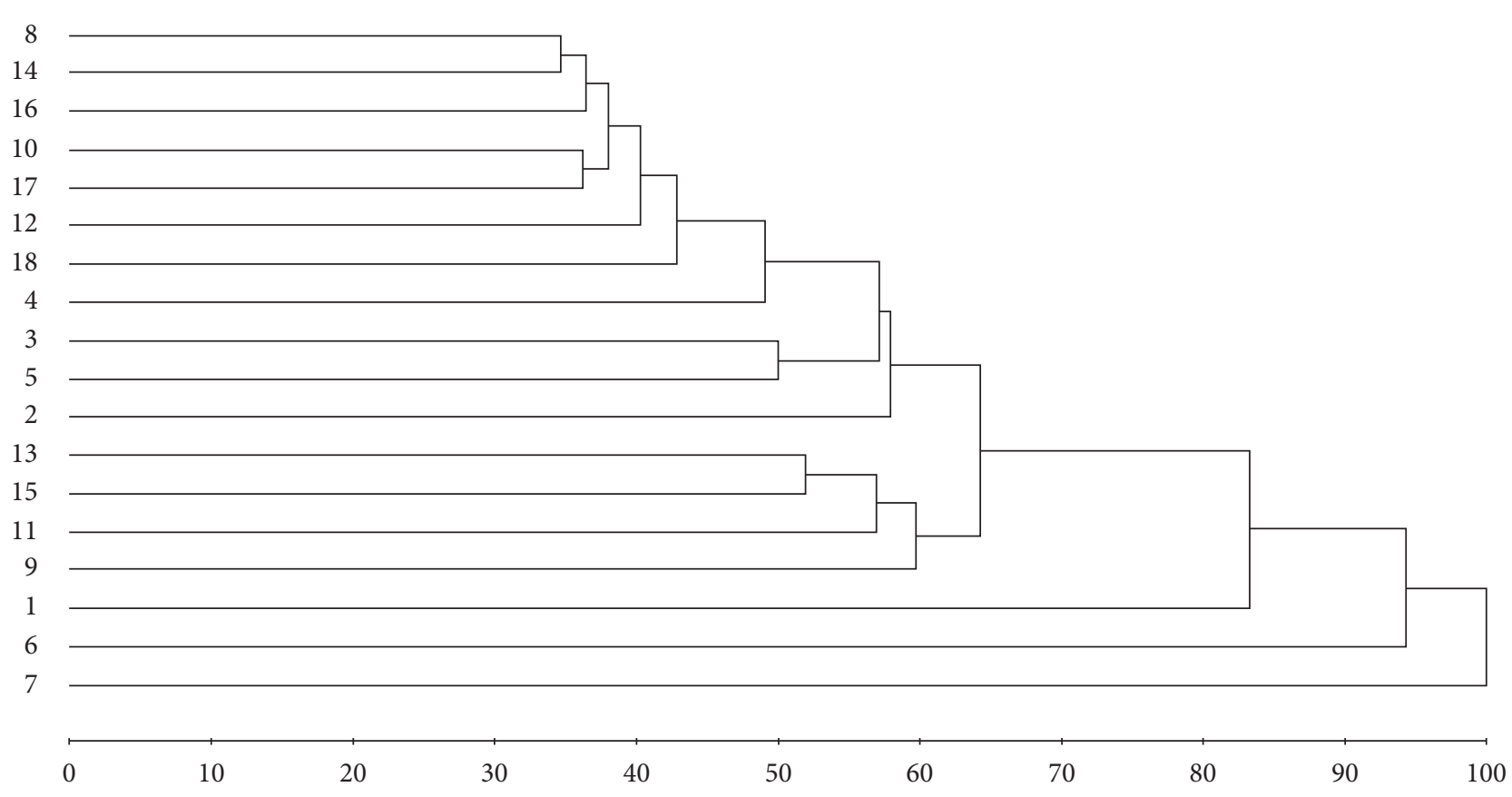

Figura 1. Dendrograma de dissimilaridade das características físico-químicas de farinha de mandioca processada em Cruzeiro do Sul - AC, estabelecido pelo método do vizinho mais próximo, utilizando-se a distância Euclidiana média padronizada, obtido a partir das 18 procedências. 
Tabela 4. Estimativas da contribuição relativa de cada característica (S.j) para o estudo da variabilidade da farinha de mandioca comercializada no município de Cruzeiro do Sul - Acre.

\begin{tabular}{lrr}
\hline \multirow{1}{*}{ Variável } & \multicolumn{2}{c}{ Contribuição Relativa } \\
\cline { 2 - 3 } & \multicolumn{1}{c}{ S.j } & $\%$ \\
\hline Carboidratos & 519,0776 & 46,82 \\
Umidade & 351,7688 & 31,73 \\
Acidez total titulável & 82,8305 & 7,47 \\
Lipídios & 64,2060 & 5,79 \\
Proteína bruta & 48,1320 & 4,34 \\
Fibra bruta & 28,1624 & 2,54 \\
Cinzas & 9,9740 & 0,89 \\
pH & 4,6112 & 0,42 \\
\hline
\end{tabular}

\section{Conclusões}

As variáveis carboidratos totais, umidade, lipídios, proteína bruta, fibra bruta, acidez, cinzas e $\mathrm{pH}$ mostram-se eficazes para avaliar a variabilidade das farinhas de mandioca;

A obtenção de grupos distintos indica presença de variabilidade na qualidade das farinhas estudadas;

A farinha peneirada, tratamento T3, produzida na comunidade Alto Pentecostes, procedente da variedade Caboquinha e a farinha do tratamento T7, produzida no Ramal da Macaxeira, proveniente da variedade Mansa e Brava, são consideradas as de melhor qualidade;

As variáveis carboidrato e umidade apresentam maior importância relativa no estudo da variabilidade físico-química de farinha de mandioca; e

As técnicas multivariadas de agrupamento são coerentes na identificação de grupos de similaridade entre as farinhas de mandioca.

\section{Agradecimentos}

Aos produtores da região de Cruzeiro do Sul - Acre, pela doação da farinha de mandioca e à FINEP pelos recursos financeiros.

\section{Referências bibliográficas}

ALBUQUERQUE, T. T. O. et al. Composição centesimal da raiz de 10 variedades de mandioca (Manihot esculenta Crantz) cultivadas em Minas Gerais. Revista Brasileira de Mandioca, v. 12, n. 1, p. 7-12, 1993.

AOAC. ASSOCIATION OF OFFICIAL ANALYTICAL CHEMISTS. Official methods of analysis of the AOAC International. 16 ed. Arlington, 1995.

ARYEE, F. N. A. et al. The physicochemical properties of flour samples from the roots of 31 varieties of cassava. Food Control, n. 17, p. 916-922, 2006.

BRASIL. Portaria n. 554, de 30 de agosto de 1995. Norma de identidade, qualidade, apresentação, embalagem, armazenamento e transporte da farinha de mandioca. Diário Oficial da República Federativa do Brasil, Brasília, DF, 01 set. 1995.

CEREDA, M. P. Produtos e subprodutos. In: SOUZA, L. S.; FARIAS, A. R. N.; MATTOS, P. L. P.; FUKUDA, W. M. G. (Ed.). Processamento e utilização da mandioca. Cruz das Almas: Embrapa Mandioca e Fruticultura Tropical, 2005. p. 17-60.

CHISTÉ, R. C. et al. Qualidade da farinha de mandioca do grupo seca. Ciência e Tecnologia de Alimentos, v. 26, n. 4, p. 861-864, 2006.

CRUZ, C. D. Programa GENES . Versão Windows - Aplicativo Computacional em Genética e Estatística. Viçosa: Universidade Federal de Viçosa, 2001. 648 p.

CRUZ, C. D.; REGAZZI, A. J. Modelos biométricos aplicados ao melhoramento genético. 2 ed. Viçosa: Universidade Federal de Viçosa, 1997. 390p.

CRUZ, C. D.; REGAZZI, J. A.; CARNEIRO, P. C. S. Divergência genética. In: CRUZ, C. D.; REGAZZI, J. A.; CARNEIRO, P. C. S. (Ed.). Modelos biométricos aplicados ao melhoramento genético. Viçosa: UFV, 2004. v. 1, p. 377-413.

DIAS, L. T; LEONEL, M. Caracterização físico-química de farinhas de mandioca de diferentes localidades do Brasil. Ciência e Agrotecnologia, v. 30, n. 4, p. 692-700, 2006.

FERREIRA NETO, C. J.; FIGUEIREDO, R. M. F.; QUEIROZ, A. J. M. Avaliação físico-química de farinhas de mandioca durante o armazenamento. Revista Brasileira de Produtos Agroindustriais, v. 5, n. 1, p. 25-31, 2003.

INSTITUTO ADOLFO LUTZ. Normas analíticas do Instituto Adolfo Lutz: métodos químicos e físicos para análise de alimentos. 2 ed. São Paulo, 1976. v. 1, 371 p.

LIMA, U. A. Manual técnico de beneficiamento e industrialização da mandioca. São Paulo: Secretaria de Ciência e Tecnologia, 1982. 56 p. (Programa Adequação).

MATTOS, L. L.; MARTINS, I. S. Consumo de fibras alimentares em população adulta. Revista de Saúde Pública, v. 34, p. 50-55, 2000.

PAIVA, F. F. A. Controle de qualidade da farinha de mandioca (Manihot esculenta Crantz) produzida na região metropolitana de Fortaleza. Fortaleza, 1991. 216 p. Dissertação - (Mestrado em Tecnologia de Alimentos), Universidade Federal do Ceará - UFC.

RAO, R.C. Advanced statistical methods in biometric research. New York: Jonh Wiley and Sons, 1952. 390 p.

RAUPP, D. S. et al. Composição e propriedades fisiológico - nutritivas de uma farinha rica em fibra insolúvel obtida do resíduo fibroso de fecularia de mandioca. Ciência e Tecnologia de Alimentos, v. 19, n. 2, 1999. Disponível em: http://www.scielo.br/scielo.php?script=sci_ arttext\&pid=S0101-20611999000200009\&lng=pt\&nrm = iso $>$. Acesso em: 30 Maio 2007.

SINGH, D. The relative importance of characters affecting genetic divergence. The Indian Journal of Genetic and Plant Breeding, v. 41, p. 237-245, 1981.

SOARES, A. G. et al. Curso de higiene e sanificação na indústria de alimentos. Rio de Janeiro: Embrapa - CTAA, 97 p. 1992. (Apostila).

SOUZA, M. L.; MENEZES, H. C. Processamento de amêndoa e torta de castanha-do-Brasil e farinha de mandioca: parâmetros de qualidade. Ciência e Tecnologia de Alimentos, v. 24, n. 1, p. 120-128, 2004. 